\title{
Exploration of the Independent Housing Experience of People with Mental Illness in a Community
}

\author{
Kim, Hee Jung ${ }^{1} \cdot$ Oh, Hee-Young ${ }^{2} \cdot$ Lee, Hyeon-Joo ${ }^{3}$ \\ ${ }^{1}$ Professor, Department of Nursing, Gachon University, Seongnam \\ ${ }^{2}$ Team manager, Gyeonggi Provincial Mental Health Welfare Center, Suwon \\ ${ }^{3}$ Senior staff, Gyeonggi Provincial Mental Health Welfare Center, Suwon, Korea
}

\begin{abstract}
Purpose: This study aims to explore the independent housing experiences of people with mental illness who receive supported independent housing services provided by the public sector. Methods: Data were collected through face-to-face interviews using semi-structured interviews. Twelve participants, who had been living independently in the community for around 11 months, were included. A qualitative descriptive method and a content analysis method were applied. Results: Independent housing experiences of people with mental illness were classified into the following four domains: house effect, growth, challenges and limitations, relationships, and support. Eleven categories included the starting point of life, environmental \& psychological comfort, inspire independence and confidence, recognition of goals and responsibilities, positive self-awareness, psychological difficulties, immaturity of daily coping, unstable self-protection, relationship improvement, and importance of support resources. Conclusion: For successful community integration of mentally disabled people, continuous legal institutional preparation for stable housing, government active interest, and flexible financial support are needed. In addition to housing support, a recovery-based independent housing case management model needs to be developed for successful maintenance of independent living. We also suggest a study on the effectiveness of independent housing to determine evidence for making a policy.
\end{abstract}

Key Words: Independent living; Housing; Persons with mental disabilities; Qualitative research

\section{서 론}

1. 연구의 필요성

국내 정신건강사업은 2017년 정신건강증진 및 정신질환자 복지서비스 지원에 관한 법률 개정 이후 정신장애인의 재활과
복지 증진을 강화하기 위해 정책적 변화를 시도하고 있으며, 정신장애인의 진정한 회복과 탈 시설화, 탈 수용화를 실현하 는데 있어 필수적인 요소인 안정적 주거에 대한 관심이 강조되 고 있다.

안정된 주거는 모든 인간의 기본 욕구로서 정신장애인에 있 어서도 예외는 아니다. 2018년 국가인권위원회의 정신장애인

주요어: 독립생활, 주택, 정신장애인, 질적연구

Corresponding author: Kim, Hee Jung https://orcid.org/0000-0001-6555-1813

Department of Nursing, Gachon University, 1342 Seongnam-daero, Sujeong-gu, Seongnam 13129, Korea.

Tel: +82-31-750-5978, Fax: +82-31-750-8859, E-mail: illine@paran.com

Received: Aug 4, 2021 | Revised: Aug 30, 2021 | Accepted: Dec 6, 2021

This is an open access article distributed under the terms of the Creative Commons Attribution Non-Commercial License (http://creativecommons.org/licenses/ by-nc/3.0), which permits unrestricted non-commercial use, distribution, and reproduction in any medium, provided the original work is properly cited. 
대상 조사에 의하면, 응답자의 약 $50 \%$ 가 궁극적으로 독립적인 주거에서 살기를 원하는 것으로 나타났으나 퇴원 후 살 곳이 없 고, 혼자 일상생활을 유지함에 있어서의 어려움 등의 문제가 있 으며, 무엇보다도 거주지 마련을 위한 재정적 문제가 큰 것으로 나타났다[1]. 또한 국내 정신장애인의 주거 인프라 현황도 대 부분 재활시설을 중심으로 이루어져 있으며[2], 이마저도 수도 권에 밀집되어 있어 공급 부족과지역 안배에 있어 불균형적인 상황이다. 따라서 정신장애인 요구에 기반한 다양한 주거서비 스를 개발하고 충분한 주거지를 확보하기 위한 주거정책 마련 이 필요하다[1,3].

정신장애인의 주거서비스 관련 연구를 살펴보면, 주거서비 스를 제공받은 정신장애인 그룹의 증상이 그렇지 않은 그룹에 비해 더 안정되었으며[4], 사회적인 기능과 약물 남용 및 충동 조절에 있어 긍정적인 결과[5]를 보고하였다. 또한 영구지원주 거 서비스를 받은 대상자들의 경우 입원률과 입원기간이 감소 한 것으로 나타났는데[6] 이러한 연구결과들은 안정적인 주거 가 중요한 요소임을 보여준다. 이와 관련하여 전문가들은 정신 장애인이 장기적으로 거주할 수 있는 주거공간과, 다양한 형태 의 주택공급이 확대되어야 한다[7]고 강조하여 왔다.

이에 정신장애인을 위한 주거지원 모델 개발 노력이 있어왔 는데, 증상과 기능 수준에 따라 감독과 통제의 수준을 결정하는 연속체주거모델(linear continuum housing model)을 시작으 로, 최근에는 감독과 통제, 주택 마련 재원의 문제, 선택과 자유 의 권리 제한 등의 문제들을 고려한 지지주거모형(supported housing model)이 강조되고 있다[8]. 지지주거모형은 지역 내 일반주거형태의 주택을 제공하고, 서비스 이용을 강제하지 않 는 유연성과 대상자의 선택권을 강조하는 모형으로 주택 지원 과 동시에 대상자의 욕구에 기반한 서비스 지원이 결합된 모델 이다. 지지주거모델은 정신장애인들이 궁극적으로 독립주거 를 선호하며[1], 독립주거가 정신장애인들의 증상과 대인관계 등에 긍정적인 변화를 이끄는[2,9] 반면, 독립생활 적응의 어려 움과 살면서 발생하는 크고 작은 위기 대응을 위해 전문가 도 움이 절대적으로 중요하다는 인식을 기반으로 성공적인 독립 주거 유지를 위해 특히 그 중요성이 강조되어 왔다 $[3,10]$. 동시 에 독립주거의 안정을 위해서 주택 확보가 관건인 만큼, 국외 의 경우 주택마련 재원과 관리 문제를 해결하기 위한 노력이 공공차원에서 시도되어 왔으나 국내의 경우는 아직 미흡한 실 정이다.

이런 흐름 속에서 최근 G도는 2018년부터 공공차원에서 공 공임대주택을 확보하여 정신장애인에게 독립주거지를 지원 하고, 동시에 전문가 사례관리서비스를 제공하는 지지 독립주
거 서비스(supported independent housing service)를 시행 해오고 있다. G도의 지지 독립주거 서비스 모델에서 주택은 지 역에 분산된 공공임대주택으로 제공하며, 기관(광역센터)이 임대주(G도)와 계약을 체결한 후 기관이 다시 대상자(주거지 원을 신청한 정신장애인 중 선정된 자)와사용계약을 체결하는 형태로 제공 된다. 동시에 대상자는 사례관리 서비스를 받는 데, 사례관리는 광역센터와주거지 당해 지역 기초센터가 연합 하여 제공하며, 주택과 관련된 제반 일들은 주로 광역이 지원하 고, 사례관리 서비스는 기초와 광역이 연합하여 제공하는 형태 이다[11]. 또한 주거 유지에 따른 비용은 보증금만 지원하며 임 대료와 그 외의 생활비를 본인이 부담하는 형태로 임대료까지 지원되는 자립생활주택에 비해 대상자에게 상대적으로 책임 과 의사결정권이 더 많이 부과된 좀 더 완전한 독립에 가까운 모델이다.

한편, 그동안 국내의 정신장애인 독립주거에 대한 연구들을 보면, 혼자 또는 동료와 함께 거주하는 정신장애인을 대상으로 한 연구들 $[9,12]$ 및 특정 정신재활시설을 기반으로 생활하며 전문가 개입의 강도와 수준이 높은 지원주거유형의 독립주거 대상자들에 대한 연구들[2,13]이 대부분이다. 따라서 본 연구 의 대상자와 같이 공공의 주택지원에 기반하고, 특정재활시설 의 서비스를 상시 이용하지 않으며, 경제적으로도 생활비는 본 인이 감당하는, 독립수준이 강화된 여건에서 생활하는 정신장 애인의 지지 독립주거(supported independent housing) 경 험에 대한 연구는 아직 시도되지 않았다.

이에 본 연구는 독립주거지 및 사례관리서비스를 제공하는 지지 독립주거(supported independent housing) 프로그램 을 기반으로 보다 완전한 형태의 독립적인 삶을 살아가는 정신 장애인의 삶의 경험을 이해하기 위해 질적 탐색적 연구를 시도 하였다. 이는 기존에 이와 같은 보다 완전한 형태의 독립주거 여건에서 살아온 정신장애인에 대한 경험의 본질에 대해 구체 적으로 알려지지 않았으므로 질적 탐색이 적합하다고 보았으 며, 이를 토대로 정신장애인의 지역사회 안착에 있어 궁극의 요 건인 진정한 독립을 성공적으로 이루어 내는데 필요한 지원 방 안을 찾고, 적합한 주거정책 마련 및 대상자 중심의 보다 세밀 한 주거서비스 전달 체계를 구축하는데 기여하고자 한다.

\section{2. 연구목적}

본 연구의 목적은 공공이 제공하는 독립주거지에서 지지 독 립주거 서비스를 제공 받으며 독립적으로 살아가는 정신장애 인의 독립주거 경험을 탐색하고 서술하는 것이다. 


\section{연구방법}

\section{1. 연구설계}

본 연구는 공공이 제공하는 독립주거지에서 지지 독립주거 서비스를 제공 받으며 독립적으로 살아가는 정신장애인의 독 립주거 경험을 탐색하기 위한 질적 서술적 연구(Qualitative descriptive study)이다.

\section{2. 연구대상}

연구대상자는 G도가 제공한 독립주거지에 거주하는 정신 장애인 중 본 연구참여에 동의한 12 명이다. G도는 독립주거지 를 $\mathrm{G}$ 도내 정신건강복지센터 또는 정신재활시설 등록자 중주거 지가 없거나 취약한 주거 환경에서 생활하는 대상자 중에서 독 립주거에 대한 욕구가 있는 자를 대상으로 지원한다. 지원대상 은 일상생활능력(위생 및 식생활관리, 금전관리 등)이 있고, 취 업이나 재활의 의지, 자립에 대한 준비성이 있어 독립생활이 가 능한 자를 우선으로 하며, 선정과정은 지원자의 신청서, 지역 사 례관리자의 의뢰서, 전문의 진단서 및 정신건강수준 관련자료 (Brief Psychiatric Rating Scale, BPRS, General Assessment of Functioning, GAF)를 바탕으로 대상자와의 면담을 진행 한 후, G도내 적합성심사 회의를 통해 선정한다[11]. 본 연구대상 은 $\mathrm{G}$ 도 지지 독립주거 프로그램이 독립거주 적응에 필요한 기
간을 최소 6 개월로 한 것을 기준으로 최소 6 개월이 지난 대상 중, 이후 안정적인 독립생활을 어느 정도 유지하고 있으며 본 연구참여에 동의한 12 명을 대상으로 하였다. 이들의 평균 거주 기간은 11.7 개월이었다.

연구참여대상자 모집 과정은 먼저 담당 사례관리자에게 본 연구의 취지와 목적을 설명하여 동의를 받았으며, 해당 사례관 리자를 통해 구두로 동의한 대상자들을 확인하였다. 구두 동의 의사를 밝힌 대상자의 명단을 전달 받은 후 연구진은 각 대상자 들에게 전화로 연구 취지와 목적을 설명하였으며, 면담 당일 최 종 연구참여에 동의한 총 12 명이 면담에 참여하였다. 참여자의 일반적 특성은 Table 1 과 같다.

\section{3. 자료수집}

자료수집기간은 2019년 8월 19일부터 2020년 11월 10일까 지였으며, 면담은 연구진이 미리 작성한 반 구조화된 질문을 기 초로 하여 개별 심층면담 형식으로 진행하였다. 면담 장소는 대 상자가 편안함을 느끼는 장소인 자택과 조용한 카페에서 이루 어졌다.

면담 질문은 독립주거를 하게 된 동기와 준비과정, 독립주거 의 삶을 살면서 경험한 전반적인 일상 및 증상관리와 관련된 부 분들, 독립주거하면서 받은 지지와 요구들, 독립주거 삶을 살 면서 생긴 변화들, 앞으로의 계획들 등 5 가지 측면으로 구성하 였다. 질문 방향과 내용의 타당성에 대한 확인을 위해 독립주거

Table 1. General Characteristics of the Participants

\begin{tabular}{llllll}
\hline No. & Gender & $\begin{array}{c}\text { Age } \\
\text { (year) }\end{array}$ & \multicolumn{1}{c}{ Diagnosis } & $\begin{array}{c}\text { Period of independent } \\
\text { residence (month) }\end{array}$ & Employment status \\
\hline P1 & Male & 38 & Schizoaffective disorder & 12 & Temporary employment \\
P2 & Female & 36 & Schizophrenia & 13 & Full-time employment \\
P3 & Female & 32 & Affective disorders, panic disorder & 12 & Unemployed \\
P4 & Female & 37 & Bipolar affective disorder & 12 & Full-time employment \\
\hline P5 & Male & 26 & Schizophrenia & 12 & Temporary employment \\
P6 & Male & 54 & Schizophrenia & 12 & Unemployed \\
\hline P7 & Male & 46 & Schizophrenia & 11 & Unemployed \\
P8 & Male & 52 & Obsessive-compulsive disorder, & 11 & Temporary employment \\
\hline P9 & Male & 57 & Schizophrenia & 11 & Temporary employment \\
\hline P10 & Male & 28 & Schizophrenia & 10 & Unemployed \\
\hline P11 & Female & 32 & Recurrent depressive disorder & 12 & Full-time employment \\
\hline P12 & Female & 36 & Recurrent depressive disorder & 12 & Unemployed \\
\hline
\end{tabular}


사례관리 관련 정신건강전문요원 3인으로부터 피드백을 받아 반영하였다.

면담 과정 중에는 참여자가 자신의 생각을 충분히 진술할 수 있도록 답변 시간을 충분히 고려하였으며, 연구자는 어떠한 편 견이나 선입견이 개입하지 않도록 주의하면서 참여자의 진술 을 경청하고 반영하면서 면담을 진행하였다. 면담 진행은 참여 자 진술이 충분하며 더 이상 새로운 주제나 추가 내용이 나타나 지 않고 포화상태에 이르렀다고 판단될 때 마무리 하였다. 면담 후 녹음된 참여자의 진술을 그대로 필사하였으며 총 면담 소요 시간은 $90 \sim 100$ 분이었다.

\section{4. 자료분석}

자료분석은 Downe-Wamboldt [14]의 내용분석단계에 따 라 진행하였다. 우선 면담자료에 대해 정확한 이해와 내면에 담 겨진 의미를 깊이 있게 확인하기 위해 각 문장과 절을 기본으로 하여 녹음과 필사자료를 3회 이상 청취하고 정독하였다. 정독 과정에서 전체자료에 대한 의미파악을 통해 5 개 주제 영역(동 기 및 각오, 긍정적 경험, 어려움들, 자원과 관계, 변화)을 1 차 도출하였다. 각 연구자들은 Atlas. ti 6.0과 엑셀 프로그램을 사 용하여 1 차 코딩을 시행하였으며, 1 차 코딩자료는 연구자 회의 를 통해 상호비교와 타당성 검토를 거쳐 정련하였다. 이후 유사 범주끼리 묶는 과정을 거치면서 초기 5 개 주제영역은 4 개의 영 역(집 효과, 성장, 남은 도전, 관계와 지지)으로 수정되었고, 4 개의 주제 영역과 범주, 1 차 코딩 자료와의 적합성을 검토 하였 다. 정련된 4 개 영역과 범주들, 1 차 코딩 자료에 대한 타당성을 확보하기 위해 질적연구 경험이 있는 간호학자 1 인에게 의뢰 하여 검토 과정을 거쳤으며(4단계) 피드백을 바탕으로 1개 명 명을 수정(도전과 한계)하였다. 이상의 수정 내용을 바탕으로 코딩과 범주의 적합성을 한 번 더 확인하고 정련하였다. 최종적 으로 4 개의 상위 범주(집 효과, 성장, 도전과 한계, 관계와지지) 와 11 개의 범주, 13 개의 하위범주를 도출함으로써 자료의 분석 을 마무리 하였고, 마지막으로 2 명의 연구참여자와 1 인의 지역 정신보건 분야 간호학자에게 의뢰하여 분석 결과에 대한 타당 성을 최종 확인하였다.

\section{5. 연구의 신뢰도와 타당도}

연구의 진정성(trustworthiness) 확보를 위해 Guba [15]가 제 시한 4 가지 측면을 고려하였다. 분석내용의 신뢰성(credibility) 을 위해 3 명의 연구자가 자료에 대한 디 브리핑 과정을 거쳤으
며, 연구참여자 2인과 간호학자 1인으로부터 피드백 과정을 거쳤다. 자료분석의 신뢰도(dependability) 확보를 위해서는 Atlas. ti 6.0, 엑셀 프로그램을 사용하여 1차 코딩을 포함한 자료분석에 활용하였다. 감사가능성(transferability) 확보를 위해서는 연구자들의 역할, 대상자 모집 및 자료수집방법과 자료분석방법을 구체적으로 제시하였다. 분석 결과의 확증성 (confirmability)을 위해서는 연구참여자 2인과 간호학자 1인 에게 회의적 검토를 거쳤다.

\section{6. 윤리적 고려}

본 연구를 위해 연구자가 속한 대학의 '연구윤리 심의위원회' 의 사전 승인을 거쳤으며(IRB No: 1044396-201808-HR-164-02), 연구참여자의 개인정보와 면담자료의 비밀유지, 본 연구목적 이외에 연구자료를 사용하지 않을 것 등을 설명하였다. 면담 시 녹음 진행을 포함하여 연구참여에 대한 서면 동의를 받았으며, 녹음 파일은 연구 종료 후에 파기할 것임을 설명하였다. 면담 중 언제든지 동의를 철회할 수 있음을 설명하였고, 면담이 끝 난 후에는 소정의 사례금을 제공하였다.

\section{7. 연구자 준비}

질적연구를 위한 연구자 준비에 있어서 본 연구진은 관련문 헌과 연구보고서들을 통해 함께 지속적으로 공부를 해 왔으며, 최근 2년 이내에 함께 내용분석을 적용한 질적연구를 등재 학 술지에 출판한 경력이 있다. 또한 각 연구진은 지역정신보건영 역에서 평균 10 년 이상의 실무와 교육, 자문 등의 역할을 해왔 으며, 대상자에 대한 민감성을 키울 수 있는 경험적 배경을 갖 추었다. 본 연구진은 책임연구자를 중심으로 질적연구 수행의 편향을 방지하고 자료에 대한 깊이 있는 의미 탐색과 효과적인 면담을 이끌어 낼 수 있기 위한 역량강화를 위해 7년여 이상 꾸 준한 면담전문가 훈련에 참여 해오는 등 질적연구수행을 이행 하기 위한 다양한 노력들을 지속해 왔다.

\section{연구결과}

독립주거를 하는 정신장애인의 경험을 탐색하기 위해 심층 면담 자료를 분석한 결과 4 개 영역, 11 개 범주와 13 개의 하위 범 주가 도출되었다(Table 2). 4개 영역은 '집 효과' , '성장', '도전 과한계', '관계와지지'로 '집 효과' 영역에는 '삶의 시작점', '환 경적 안위', '심리적 안위'의 3개의 범주가 도출되었으며, '성 
Table 2. Categories and Subcategories of Independent living Experience of People with Mental Disabilities

\begin{tabular}{lll}
\hline Domain & \multicolumn{1}{c}{ Category } & \multicolumn{1}{c}{ Subcategory } \\
\hline House effect & Starting point of life & - Starting point for living a meaningful life \\
& Environmental comfort & $\cdot$ Having a suitable and good environment \\
& Psychological comfort & $\cdot$ Experiencing psychological comfort and symptom stability \\
\hline Growth & Inspiring independence and confidence & $\cdot$ Gaining independence and self-confidence in coping \\
& Recognition of goal and responsibility & $\cdot$ Recognizing responsibility and looking back on the present \\
& Positive self-awareness & and future \\
\hline $\begin{array}{l}\text { Challenges and } \\
\text { limitations }\end{array}$ & Psychological difficulties & $\cdot$ Improving self-directedness and self-esteem \\
& Immaturity of daily coping & $\cdot$ Loneliness and anxiety \\
\hline $\begin{array}{l}\text { Relationship and } \\
\text { support }\end{array}$ & Unstable self-protection & $\cdot$ Feelings of guilt and depression due to economic instability \\
& Relationship improvement & $\cdot$ Trial and error in managing money and daily life \\
\hline
\end{tabular}

장' 영역에는 '독립심과 자신감 유발', '목표와책임인식', '긍정 적 자기인식'의 3 개 범주가 도출되었다. '도전과 한계' 영역에 는 '심리적 어려움' , '일상대처의 미숙함', '불안정한 자기보호' 의 3개 범주가, '관계와 지지' 영역에는 '관계개선', '지지자원 의 중요성'이 도출되었다.

\section{1. 집 효과}

집 효과 영역에는 '삶의 시작점', '환경적 안위', '심리적 안 위'가 포함되었다. 집 효과와 관련하여 참여자들은 거주할 집 이 생김으로서 자기 생활과 미래에 대한 기대가 생기며, 의미 있는 삶을 살게 되는 삶의 시작점이 되었다고 보고하였다. 또한 좋은 물리적 환경을 누리게 되어 환경에 대한 만족감을 느끼고, 심리적 편안함과 증상의 안정을 느끼는 등 환경적, 심리적 안 위를 경험하였다.

\section{범주 1. 삶의 시작점}

\section{하위범주 1. 의미 있는 삶을 사는 시작점이 됨}

저는 뭐랄까 큰 무게가 풀리는 느낌이었어요. 집 문제 가 해결되면서 제 생활이나 미래의 문들이 열리고, 돈 문 제도 그렇고, 여유가 생기고, 여러 희망이 생기면서 꿈들 이 열리는(것처럼) 그런 문들이 열리더라고요.(참여자 7)
여기서 5년 밖에는 못살지만 굉장히 큰 게, 값진 삶을 사는 것 같아요. 아주 긴 시간을 여기서 살 수 있다는 생각 이 들었어요.(참여자5)

이(주거) 서비스가 첫 출발이에요. 보호관찰 끝나고 이 제 첫 출발이면서 첫 경험이고(삶의)그 발단이 되는거에 요.(참여자 9)

\section{범주 2. 환경적 안위}

\section{하위범주 1. 적합하고 좋은 환경을 누림}

집이 많이 좋아요. 1년 살고 건강도 좋아지고, 기분이 되게 좋았어요. 창문도 많고 햇빛도 잘 들고, 구조도 되게 좋아서 처음 입주하고 계속(집안을) 돌아다녔어요. 거실 도 있고 투 룸이에요.(참여자 2)

처음 딱 들어갔을 때 벽지도 장판도 되게 깔끔하고, 싱 크대도 깨끗하고, 집이 전체적으로 깨끗하고 좋더라고요. 혼자 지내기에 딱 적당했어요. 너무 넓지도 않고 너무 작 지도 않고.(참여자 4)

집이 기대보다 더 좋았어요. 제가 운이 좋다. 집이 괜찮 다 생각했고. 집이 깨끗하고 벽지도 새로 했고, 공간도 좋 고, 처음에 들어가서 아 고맙다는 생각이 들더라고요.(참 여자 7) 


\section{범주 3. 심리적 안위}

하위범주 1. 증상이 안정되고 심리적 편안함을 누림

주거가 안정이 안 될 때는 되게 불안하고 위축되고 힘 들었어요. 마음이 편해진 게 제일 큰 변화인 것 같아요. 집 주인 눈치 안 봐도 되고, 안정되게 정부에서 지원해주니 까 마음이 편해진 것 같아요. 거의 $80 \%$ 회복에도 영향 받 는 것 같아요. 신체적으로도 그렇고 일단 생각하는 게 틀 려졌어요.(참여자 11)

솔직히 저는 (독립주거 전에는) 증상이 잘 안 낫는 것 같았어요. 폐쇄공포증이나 환청, 공황증상 같은 게 있고 몸이 많이 안 좋았어요. (그런데) 집에서 살다 보니 치료가 되는 그런 느낌이 들고 지금은 많이 좋아진 것 같아요. 계 속 약도 먹고 지으러 가려고 생각하고 있어요.(참여자 2)

안정적인 집이 증상에 도움 된다고 많이 느껴요. 진짜 도움 많이 받았어요. 혼자 살아보면서 부딪치면서 증상이 점점 나아지는 걸 느껴요.(참여자 4 )

\section{2. 성장}

성장 영역에는 '독립심과 자신감 유발', '목표와 책임인식', ‘긍정적 자기인식'이 포함되었다. 성장과 관련하여 참여자들 은 독립생활을 하면서 되도록 스스로 대처하려는 노력을 통해 독립심과 대처에 대한 자신감을 갖게 되었으며, 현재와 미래의 해야할 바를 돌아보면서 책임감을 인식하게 되었다. 또한 자기 주관이 생기고 어른이 된 것 같으며, 자존감이 향상되는 등 긍 정적인 자기 인식에 대한 경험을 보고하였다.

\section{범주 1. 독립심과 자신감 유발}

하위범주 1. 독립 의지가 생기고 대처에 자신감을 갖게 됨 일단은 혼자고, 집이 있으니, 공과금이랑 먹는 거랑 해 결해야 되니, 경제적인 게 많이 컸어요. 아무래도 (돈쓰는 게) 눈에 보이니까 뭔가 일을 해야 되니 취업이 연관이 되 고 (취업하려는) 원동력이 되는 거죠. 독립심이 강해지고 요.(참여자 4)

(독립주거는) 굉장히 좋은 경험이에요. 자기 관리를 잘 하려고 노력하게 되요. 의지하는 것 보다 독립심을 키우 는 노력이요.(참여자 3)

(독립주거가) 도움이 많이 되는 것 같아요. '내가 어떻 게 살아야 될지, 내가 이 부분은 너무 힘들었는데, 이 부분
은 이렇게 대처를 하면 될 것 같아.' 라는 그런 게(자신감) 생기는 것 같아요.(참여자 12 )

\section{범주 2. 목표와 책임인식}

하위범주 1. 현재와 미래를 돌아보며 책임감과 목표를 인식함 일단은 나만의 시간을 가지면서 (내가 지금) 뭘 해야 할 지 생각을 많이 하게 되더라고요. 앞으로 애들을 키우고 돌봐야 하거든요. 그러려면 (제가) 많이 바뀌어야 하니까 요. 이렇게 막 암울하게 시간을 보내면 아무것도 될 수가 없다고 생각했어요.(참여자 4)

더 이상 (현재) 생활 패턴이랑 삶의 목표가 어긋나면 앞 으로 살아가기 어렵겠다고 생각했어요. 그래서 가끔 '왜 내가 그걸 안했을까' 이런 생각 하면서 고치려 하는데, 어 렵지만 지금도 노력하고 있어요.(참여자 5)

\section{범주 3. 긍정적 자기인식}

\section{하위범주 1. 자기주도성과 자존감 향상}

자존감이죠. 자존감이 좋아졌어요. 집이, 이렇게 편안 장소가 있다는 게, 이 집에 살면서 좋은 생각이 드는 것 같 아요.(참여자 6)

전에는 몸은 어른이었는데, 마음은 그냥 애였던 것 같 아요. 그런데 이제는 애가 아닌 어른으로 나아가는 것 같 아요. 혼자 살면서 '이거는 이거고. 저거는 저거.' 라는 제 주관이 생겼고, 예전에는 그냥 (남에게) 끌려 다녔다면 지 금은 아니에요.(참여자 12)

\section{3. 도전과 한계}

도전과 한계 영역에는 '심리적 어려움', '일상대처의 미숙 함', '불안정한 자기보호' 가 포함되었다. 참여자들은 독립생활 을 영위하면서 외로움과 불안감, 경제적 요소의 불안정으로 인 한 자책감과 우울감을 보고하였다. 또한 돈 관리를 포함하여 일 상의 일들을 처리함에 있어 미숙함을 토로하였으며, 무엇보다 도 규칙적인 투약이 어렵고, 자살사고가 생기기도 하는 등 자 기보호에 있어 불안정해지는 상황에 놓이기도 하였다.

\section{범주 1. 심리적 어려움}

하위범주 1. 혼자된 외로움과 불안감 
(혼자 살면서) 막연하게 '혹시 무슨 문제가 생기지 않을 까?' 라는 그런 걱정이 들었던 것 같아요.(참여자 10)

좀 외롭단 생각이 들어요. 공허한 것도 가끔씩 있고요. (사람들이) 없어지고, 또 가고 나면, 지나고 나면(다시 혼 자이고).(참여자 1 )

이웃과는 그냥 별로 이상 없이 친절하게 대하려고 하는 데 카드 비번으로 (집 문을) 열고 하니까 그게 좀, 약간 무 섭긴 해요. 심리적으로 누가 열고 들어올까 봐 불안해요. (참여자 2)

\section{하위범주 2. 경제적 불안정으로 인한 자책감과 우울감}

나이가 마흔이 다 되어가니 좋은 직장에 취직하기도 힘 들고 '내가 이것밖에 안되나?' 그런 생각도 솔직히 들고, 기분이 다운되고 자책감이 많이 들어요. 부담감도 많고 요. 가장 중요한 게 경제적인 문제잖아요. 그게 안정이 안 되니까.(참여자 1)

제가 취업에 실패 했거든요. 부모님도 일이 없으시고 동생도 벌이가 좋지 않아요, 제가 맏이라 경제적으로 안 정이 되어야 되는데, 그게 안 되니까 자책감이 들어요.(참 여자 3)

독립 후 그냥 우울했던 것 같아요. 몸도 막 힘들고 그래 서 잠만 자려고 하고, 좀 힘들었던 것 같아요. '내가 왜 이 렇게까지 왔어야 되나?' 하는 생각? '내가 열심히 살면 이 렇게까지 안 됐을 텐데 왜 나만?' 이런 생각이 들 때. 좌절 감이라고 해야 되나?(참여자 11)

\section{범주 2. 일상대처의 미숙함}

\section{하위범주 1. 돈과 일상생활 관리에서의 시행착오}

첫 월급을 타서 몽땅 태블릿 PC를 산 적이 있어요. 그랬 더니 왜 그렇게 철이 없냐고 (그런 소릴 들었어요). 힘들긴 했어요. 불필요한 거를 살 때도 있고 그랬어요.(참여자 5)

이사하고 유플러스랑 통화하는데 그 말을 못 알아들은 거예요. 뭘 설치 할 건지를 묻는데 제가 잘 모르니까, 그 전 화 받으면서 '이건 아닌 것 같다'는 생각이 들어, 그냥 거 절하고 싶었는데 그걸 거절을 못했어요. 그냥 끌려갔죠. 금융관계 주식관계 이야기 나오면 확 쫄게 되더라고요. (참여자 6)

수도꼭지가 고장 나면 그런 것도 내가 해야 되고, 아니 면 (사례관리자) 선생님한테 이야기해야 되는데 좀 미안 한 감이 있어서 어떻게 할 줄을 모르겠는 거죠. 나도 이제
나 혼자 스스로 해야 되는데 아직까지는 적응이 안 되니 까, 헤쳐 나가는 방법을 아직 잘 모르는 게 어려운 점이에 요.(참여자 12 )

\section{범주 3. 불안정한 자기보호}

하위범주 1. 불안정한 투약과 잠재된 자살위기 약을 까먹을 때가 너무 많아요. 그리고 먹었는데 또 먹 을 때도 있어요. 먹었나? 안 먹었나? 기억이 안날 때도 있 어요. 약 먹고 나면 숫자를 써놔야 할 것 같아요.(참여자 11)

독립해서 1 년 살면서 자살하고 싶다는 생각이 든 적이 있어요. 사례관리자 선생님한테 '두 번 다시 약 먹지(자살 시도) 않겠다.' 고 약속을 했고 스스로도 '(자살시도하면) 안 된다. 안 된다.' 하는데도 한 번씩 무너질 때는 '아, 어떻 게 하지?'하는 생각이 들고, 다시 맘을 다잡지만 나쁜 짓 (자살시도)을 했을 수도 있겠다는 생각이 들어요. 우울감 이 솔직히 돈 때문에 많이 온 것 같아요.(참여자 12)

혼자 있다 보니 자살 충동이 들어서 시도를 한번 한 적 이 있었는데, 그런 게 좀 위험한 것 같아요. 직장에서 갈등 이 생겼는데 6 개월을 채워야 실업 급여를 받을 수 있어서 6월 말까지 일을 하게 해달라고 했는데, 되게 안 좋은 표정 으로 생각해 보겠다는 거예요. 그래서 앞으로 살날이 (경 제적으로) 너무 막막해서 안 좋은 생각이 들었었어요.(참 여자 3)

\section{4. 관계와 지지}

관계와 지지영역에는 '관계개선', '지지자원의 중요성'이 포 함되었다. 참여자들은 독립주거를 하게 되면서 가족과의 관계 가 많이 개선되었으며 지역 자조모임과 동료들과의 소통이 도 움이 되었다고 보고하였다. 무엇보다도 독립주거 적응과정에 서 사례관리자의 지속적인 지지와 상담이 큰 도움이 되었다고 보고하였다.

\section{범주 1. 관계개선}

\section{하위범주 1. 가족과의 관계가 개선됨}

부모님과의 관계가 많이 좋아졌어요. 어머니께서 옷 입 는거, 이빨 닦는 거까지 혼을 많이 내셨는데, 부모님이 안 계시니까 사이가 더 좋아졌어요. '왜 이빨 안 닦냐 이빨 좀 
닦아라.' 그런 말 들어도 별로 기분 상하지 않고 오히려 고 맙게 느껴져요. 혼자 살다보니까.(참여자 5)

부모님은 제가 독립생활을 잘 할지 걱정을 많이 하신 것 같아요. 독립하고 나서 부모님하고 같이 있는 시간이 좀 더 늘었어요. 지금은 부모님 집에 가면 같이 내 애기도 하고, 같이 티비도 보고 그런 게 조금 나아진 것 같아요. (참여자 6)

제가 이렇다고 하면 (부모님이) 이렇다, 저렇다 하면서 대화도 해주시고 저를 존중해주세요. 그리고 가끔 옛날 떠올리면서 부모님께 감사하고 죄송하다고 말씀 드려요. 그러면 부모님이 ‘허허허' 그러십니다.(참여자 10)

\section{범주 2. 지지자원의 중요성}

\section{하위범주 1. 자조모임과 소통의 중요성}

(자조모임에서) 취업에 대한 이야기도 나누고, 취업성 공패키지로 자격증 따는 분도 있어서 그런 이야기도 듣 고, 자취하면서 필요한 팁 같은 것도 듣기도 해요. 뭐 음식 물쓰레기를 냉동실에 넣고 보관하면 좋다거나.(참여자 3)

O O 기관에서 해주는 사례관리나 자조모임이 도움이 되었어요. 소속감(도 느끼고), 여가생활도 할 수 있고요. 그게 아니었으면 아마 주말이나 그럴 때 혼자 있는 시간이 많고 그거를(여가를) 해결 못했을 것 같아요.(참여자 6)

(사례관리자를) 자주 뵙고 싶은데 어려우니 유튜브 같 은, 이런 데서 독립주거 하시는 분들 어떻게 생활하시는 지 올려주면 좀 좋을 것 같아요. 어떻게 생활하시는지 내 가 몰랐던 거를 배울 수 있을 것 같아요. 내가 놓치는 부분 을 선생님들한테 계속 요구하지 않아도 되고 그런 게 너무 좋을 것 같아요.(참여자 12 )

\section{하위범주 2. 사례관리 서비스의 중요성}

(처음에) 집에 대한 적응을 아예 못해서 너무 힘이 들었 어요. 힘에 부치기도 하고 '이거 어떻게 해야 하나', '어떻 게 생활해야 되나' 그랬는데, 사례관리자 선생님이 '잘하 고 있다' ' '조금만 더 잘하면 될 것 같다'고 계속 용기를 주 시는 거예요. 거의 정신적 지주처럼 선생님들이 하나부터 열까지 세심하게 챙겨주시는 부분이 지금도 너무 감사해 요.(참여자 12 )

(사례관리자) 선생님이 한 번씩 오셔서 상담 비슷하게 하는데 되게 도움이 많이 돼요. 힘들 때 이야기를 하면 잘 들어주시고, 그럴 때는 어떻게 지내야 하는지도 조언도
해주시고, 도움이 많이 돼요.(참여자 3)

사례관리자 선생님이 상담도 잘해주시고, 배려도 많이 해주시고 도움을 많이 받고 있어요. 선생님들 덕분에 제 가 이렇게 살고 있어요. 선생님께서는 일자리를 빨리 잡 아서 제가 잘 생활하기를 바라세요.(참여자 10)

\section{논 의}

정신장애인의 독립주거 경험을 탐색하기 위해 면담 자료를 분석한 결과 '집 효과', '성장', '도전과 한계’, '관계와지지'의 4 개 영역이 도출되었으며 도출된 4 개의 영역과 범주 및 하위범 주가 시사하는 바에 대하여 순차적으로 논해보고자 한다.

'집 효과'와 관련하여 참여자들은 거주할 집이 생긴 것이 삶 의 시작점이 되었으며, 깨끗하고 좋은 환경에서 심리적 편안함 을 얻게 되는 환경적, 심리적 안위를 경험하였다.

참여자들은 거주할 수 있는 공간이 생긴 것 자체만으로도 꿈 들이 열리고, 인생의 값진 첫 출발을 하게 되었다고 하였다. 선 행연구는 정신장애인들에게 집이 생긴다는 것은 정착을 위해 더 이상 표류하지 않아도 된다는 안도감을 주는[12] 중요한 요 소이며, 진정한 회복을 위해 제 2 의 삶을 개척해 나가는 전환점 [16]이 된다고 하였다. 또한 참여자들은 좋은 물리적 환경에서 기분향상과 만족감을 얻고, 심리적 편안함과 증상 안정을 경험 하였다. 본 연구참여자들은 독립에 대한 욕구는 있으나 안정적 거처가 없어 시설이나 고시원에 머물던 분들로, 국내 대다수 정 신장애인들의 거주 여건이 매우 열악한 상황임을 볼 때, 기본적 안위 제공 측면에서 좋은 환경의 주거지를 마련하는 것은 시급 한 과제라 하겠다. 선행연구도 독립주거서비스를 받는 대상자 들이 시설과 기관의 보호를 받는 대상들보다 삶의 질과 만족도 가 더 높다[17]고 보고하는 바, 질 좋은 주거지 확보를 통해 독 립의 기회는 물론, 심리적, 증상적으로 안위를 수반하면서 회 복을 이끌어 갈 시작점을 제공할 수 있는 국가적인 차원에서 의 노력이 필요하다 하겠다.

'성장'과 관련하여 참여자들은 독립주거를 통해 독립심과 대처에 대한 자신감이 생기고, 현재와 미래 삶의 목표 및 행동 실천에 대한 책임감을 인식하였다. 아울러 자기 주관을 갖게 되 는 자기 주도성과 자존감 향상의 긍정적인 자기인식 변화를 경 험하였다.

독립심과 관련하여 참여자들은 특히 경제적 독립과 취업에 대한 의지를 표명하였으며, 동시에 어떻게 살아가야 할지에 대 한 대처에 있어서도 할 수 있다는 자신감을 표현하였다.

독립심은 독립에 대한 의지로, 의지는 변화모델(trans-theo- 
retical model of change)에 근거해 볼 때, 변화(독립)의 필요 성에 대한 인식, 즉 변화(독립)동기가 유발된 것을 의미한다 [18]. 변화 동기(motivation to change)는 회복모델에 포함된 중요한 요소로[18], 동기가 인지와 행동실천(기능)을 매개하는 주요 요인이나 조현병에서는 동기 유발이 주요 장애로 인식되 어[19] 왔다. 따라서 독립주거 대상자들에게 행동의 시작과 유 지를 이끄는 심리적 자원인 독립에 대한 동기가 유발된 것은 주 목할 부분이라 하겠다. 아울러 참여자들은 일상 대처에 대한 자 신감을 표명하였는데, 선행연구도 지지주거에 참여한 정신장 애인들이 계획한 일정을 수행하고, 스스로 스트레스를 관리하 면서 독립에 대한 자신감을 얻었으며 $[13,20]$, 독립주거 당사자 들에게서 관찰된 큰 변화는 스스로 삶을 통제하고 자신감을 갖 게 된 것[3]이라고 보고하였다. 자신감은 목표 달성을 위해 장 애물을 이기고, 행동, 조절하는 자기 역량에 대한 믿음으로 역 시 회복과정에서 관찰되는 중요한 심리변수이며, 회복과정에 서 자신감 개발을 돕는 것은 중요하다[21]. 따라서 독립주거 참 여자들이 자신감과 같은 긍정적인 심리적 역량을 보고한 점은 성공적인 독립 유지를 기대하는 관점에서 의미 있는 결과라 하 겠으며, 사례관리 과정에서 보다 세밀한 관심을 두고 지지해야 할 부분이라고 생각한다.

참여자들은 또한 자신의 현재와 미래를 돌아보며 삶의 목 표를 인식하고 이를 위해 해야 할 바에 대한 책임감을 인식하 였다. 선행연구는 독립생활 당사자들이 거주지가 자신의 집 이라고 생각할 때 일상에 대해 책임감과 목표의식을 가지고 [12], 내 삶은 내가 책임진다는 각오를 하였음을 보고하였다 [2]. 목표설정은 어떤 일을 순서적으로 해 나가는데 필요한 집 행기능(executive function)으로 조현병 환자들이 흔히 어려 움을 겪고 있는 사회적 기능문제 중 하나이며, 책임감은 회복의 과정 중의 임파워먼트를 설명하는 주요 특징이다[18]. 따라서 본 연구참여자들의 이와 같은 보고는 참여자들이 독립주거를 통해 회복의 주요 요소와 중요한 사회적 기능들을 자연스럽게 내재화 해나가고 있음을 짐작해 볼 수 있는 결과라 하겠다.

아울러 참여자들은 독립주거 생활과정에서 자존감이 향상 되었으며, 자기주관을 갖고 자기 주도적으로 행동하는 긍정적 자기인식의 변화를 보고하였다. 자존감도 정신장애인의 회복 연구에서 보고되는 중요한 변수로 특히 낙인감과 부적 상관이 보고된[22] 심리적 변수다. 사회적 낙인은 특히 주택과, 고용, 대인관계 등의 영역에서 차별의 원인이 되고 있는데, 정신장애 인의 장기고용이 자기낙인감(self-stigmatization)을 감소시 키며, 자존감과는 정적 관련이 있다[22]는 연구결과를 볼 때, 본 연구의 주택 제공과 긍정적인 자존감과의 관계를 같은 맥락
에서 유추해 볼 수 있다. 이상 성장영역에 포함된 독립심, 자신 감, 목표와책임인식, 긍정적 자기인식은 선행 회복연구들에서 제시한 개념들로[18], 참여자들이 독립적인 삶을 살면서 회복 의 내적 성장을 경험하고 있음을 알 수 있었다. 따라서 향후 독 립주거가 정신장애인의 회복에 미치는 영향의 관점에서 관심 과 연구가 필요하며, 독립주거 대상자 사례관리에서는 회복의 관점에서 회복단계를 고려한 사례관리 전략을 고려할 필요가 있다고 본다.

한편, '도전과 한계'와 관련하여 참여자들은 혼자라는 외로 움과 불안감, 경제적 현실에 직면하면서 자책감과 우울감 등 심리적 어려움을 경험하였다. 또한 일상에서 돈 관리를 포함하 여 일상대처에서의 미숙함을 보고하였으며, 규칙적으로 투약 하는 것이 어렵고, 때로는 자살 위기에 직면하는 등 스스로 자 기를 보호하는데 있어 불안정함을 경험하고 있었다.

심리적 어려움과 관련하여 선행연구는 정신장애인들이 동 료들과 함께 생활하다가 독립하게 되면서 외로움을 경험하며 [2,9,12], 자신을 돌봐주던 시설 직원과 가족들을 그리워한다 [9]고 하였다. 집과 독립이 삶에 안정을 주는 요건이지만 진정 한 삶의 안정이 완성되기 위해 이면의 고독감과의 균형이 요구 되며, 이를 위해 적절한 사회접촉과사회망을 유지할 수 있도록 돕는 것이 중요하다[23]. 따라서 적절한 사회망이 양적, 질적으 로 유지될 수 있도록 사례관리 과정에서 이에 대한 세심한 관찰 과 지원계획이 당사자와 함께 마련되어야할 것이다. 또한 참여 자들은 막상 취업이 어렵고 경제적 안정을 이루기 어려운 현실 에 직면하면서 본인을 자책하고 우울해하는 등 심리적인 어려 움을 함께 보고하였다. 정신장애인들은 취업을 유지하는 경우 에도 낮은 소득으로 인해 경제적 어려움에 직면하는데, 국내 정 신장애인 가구의 월평균 소득은 전체 장애유형 중 가장 낮으며, $56.3 \%$ 가 국민기초생활보장 수급대상 중에서 2 번째로 빈곤한 집단으로 나타났다[1]. 따라서 독립한 정신장애인들이 경제적 인 최저 근간을 유지하며 살아갈 수 있도록 고용과 재정지원에 대한 상호 유연성 있는 지원책이 모색되어야 할 것이다.

일상대처의 미숙함과 관련하여 참여자들은 생활비를 부적 절하게 소비하거나, 통신, 금융 및 수도 고장 같은 일상의 일에 대처할 때 어려움이 있었다. 선행연구는 독립생활을 하는 정신 장애인들이 청소나 식사준비 등의 일상활동을 꾸준하게 수행 하는 것에 어려움이 있으며 $[2,12]$, 특히 독립 초기에는 한계가 있다고[9] 보고하였다. 정신장애인들의 일상생활기능은 독립 생활을 영위하는데 중요한 부분이나, 주의집중과 기억력 저하, 정보처리과정의 지연, 집행기능(executive function)의 손상 등으로 인해 독립생활에 제한을 경험한다[24]. G도의 경우, 이 
러한 점들을 감안하여 입주적응기(2주)와 입주초기(6개월) 기 간에 각각, 주 1 회 이상, 주 1 회 간격으로 사례관리를 통한 적응 지원을 하고 있다. 한편, 최근 연구는 재정관리, 전화사용과 같 은 집행기능을 돕기 위해 삶의 실제 장면에서 적용한 인지적 중 재가 도구적 일상생활(instrumental activity daily living)능 력과 집행능력 향상에 효과가 있음[25]을 보고하였다. 즉, 독립 주거 대상자들에게도 여전히 일상생활기능에 대한 지지 요구 가 존재하는 만큼, 사례관리 간격과 빈도를 고려하는 것 외에 구체적 중재효과를 보고하는 선행연구들을 기반으로 하여 실 재 독립주거 일상에서 적용할 수 있는 일상생활능력 증진을 위 한 대상자별 맞춤형 중재 전략을 사례관리 과정에서 개발하고 적용해 볼 필요가 있을 것이다.

불안정한 자기 보호와 관련하여 참여자들은 규칙적인 투약 이행의 어려움, 자살사고와 자살충동 경험을 보고하였다. 투약 이행 또한 독립주거를 성공적으로 해나가는데 가장 기본이 되 는 요소로 선행연구는 독립생활자들이 약을 거르지 않고 잘 복 용하기 위해 노력한다[2]고 보고 한 바 있다. 본 연구참여자들 도 대부분 투약의 중요성은 인식하고 있었으나, 투약을 빠뜨리 거나 혹은 기억하지 못하고 중복 복용하는 경우가 있었다. 따라 서 대상자별로 투약을 유지하지 못하는 이유와 형태를 잘 파악 하는 것이 중요할 것이며, 개별적인 세밀한 중재가 필요할 것 이다. 자살위기와 관련해서는 특히 경제적인 어려움과 관련하 여 언급하였는데, 이로 인한 우울과 자살충동 제어의 어려움으 로 위기상황을 경험하였다. 이상과 같은 투약 누락과 중복 복 용, 자살의 위험 등은 유연한 지지와 즉각적인 도움을 제공받 기 어려운 독립주거 상황[16]에서 한계이고 도전이다. 특히 자 살은 국내 정신장애인의 사망원인 2위, 자살률도 전체 인구보 다 8배나 높은 실정으로[26], 선행연구는 낮은 경제 상태에 대 한 지각과 낮은 소득을 정신장애인의 주요 자살요인으로 보고 해 왔다[27]. 독립주거가 당사자들의 삶에 중요한 요소지만 경 제적인 부분과 같은 기본적인 문제들을 보조받을 기회를 잃지 않는 것 또한 중요하다[23]. 따라서 경제적인 부분과 투약유지 에 대한 부분은 독립주거 사례관리 전략에서 중요하게 고려되 어야 할 것이며, 특히 독립주거 당사자가 고용된 상황일 경우에 도, 최저 생활비가 유지될 수 있도록 탄력적으로 재정이 지원될 수 있는 제도적, 정책적 방안을 고민해야 할 것이다.

'관계와 지지'와 관련하여 참여자들은 가족과의 관계가 개 선되었으며, 자조모임 등의 자원을 통해 살아가는 지혜에 대해 소통하고, 전문가들로부터 지속적인 사례관리를 받는 것이 큰 지지가 되었음을 보고하였다.

관계개선과 관련하여 참여자들은 독립 후 부모로부터 일상
에서 지적을 받는 부정적 경험을 덜 하게 되고, 자신을 염려하 고, 존중해주는 부모의 태도변화 속에서 가족과의 관계가 개선 되는 경험을 하였다. 선행연구도 독립생활 당사자들이 부모로 부터 독립을 이루고 난 후 관계가 개선되었음을 보고한 바 있 다[20]. 정신질환자와 가족과의 관계는 정서표출(Expressed Emotion, EE) 개념으로 연구되어 왔는데, 선행연구는 가족의 부정적 정서표출(high EE)이 만성 환자의 재발과 관련이 크고, 초발 정신증 환자 가족의 경우는 부정적 정서표출 가족기능이 관찰되었음을 보고하였다[28]. 이처럼 가족의 정서표출(EE) 연구는 질병과정 즉, 만성과 초발의 시점에서 연구되었는데, 선 행연구는 만성과 초발 환자 가족에게서 관찰되는 부정적 정서 표출의 원인이 서로 다르므로 이에 기반 하여 가족중재가 이루 어져야 한다고 제안하고 있다[29]. 질병과정의 관점에서 볼 때 본 연구참여자들은 독립주거를 시도하는 적극적인 회복과정 시점이라 할 수 있으며, 이들 가족의 정서표출의 기저는 만성 환자(높은 스트레스와 부담감)나 초발 환자 가족들(상실과 슬 픔에 대한 대처)[28] 기저와는 다를 것을 예측해 볼 수 있다. 즉, 본 연구참여자들이 자신에 대한 가족의 정서와 태도를 긍정적 으로 보고한 만큼, 독립주거 당사자 가족의 정서와 인식을 이 해할 필요가 있으며, 향후 독립주거 당사자 가족에 대한 연구를 통해 관련 요인을 확인하여 당사자 회복을 돕기 위한 가족 중재 근거를 마련하는 시도가 필요하리라 본다.

또한 참여자들은 주말에는 지역 자조모임에 참여하면서, 동 료들과 일상생활이나 취업에 관한 정보들을 소통하고, 소속감 을 느꼈으며, 무엇보다도 사례관리자의 상담과 지지, 격려가 큰 도움이 되었다. 동료와 지역사회 지지, 전문가 지지는 보다 독립적인 주거로 옮겨가도록 돕는 주거서비스 제공과정에서 중요한 요소이다[16]. 선행연구는 독립주거 당사자들이 시설 거주 당사자들보다 제공된 사회적 지지에 대한 인식이 높았고, 따라서 사회적 지지에 대한 인식도에 따라 지지망과 네트워크 제공 등의 지지형태를 세밀하게 제공해야 한다고 제언하였다 [30]. 본 연구참여자들의 경우 독립생활을 잘 유지하기 위해 사 례관리와 지지의 중요성을 잘 인식하고 있으며, 유튜브와 같은 매체를 통한 지지방식을 제안하는 등 지지자원에 대한 욕구가 큼을 알 수 있었다. 따라서 지지를 제공함에 있어, 지지자원에 대한 요구와 정도를 고려하고, 특히 최근 COVID 19로 인한 비 대면 상황에서 꼭 필요한 지지가 무엇이며, 어떤 형태로 지지가 제공될 때 안정되고 효과적일지에 대한 세밀한 고려가 필요하 다 하겠다.

본 연구는 일개 도에서 시행하는 독립주거 프로그램에 참여 한 일개 지역 참여자를 대상으로 하여 해당 모집단이 제한적이 
라는 점과 개별 대상자의 기능수준과 회복 여정의 차이, 대처수 준의 차이가 있다는 점을 고려해하는 제한점이 있다.

이상을 토대로 실무, 연구, 정책의 관점에서 다음과 같은 제 언을 하고자 한다. 첫째 실무 측면에서는, 사례관리가 지지 독 립주거모형에서 중요한 요소이고 선행 회복연구에서 보고된 의미 있는 개념들이 독립주거 경험으로 보고된 만큼, 회복단계 와 과정을 고려한 회복관점기반 독립주거 사례관리 모형을 개 발할 필요가 있다. 아울러 독립주거 사례관리자 역량 준비에 있어서도, 회복증진관계 능력과 같은 보다 전문적인 정신건강 실무자의 회복실무역량을 검토하고 개발하는 것에 대한 재고 가 필요하다. 다른 한편으로는 독립주거상황에서도 위기요인 (투약유지와 자살위기)이 내재되어 있으므로, 적시에 지지가 제공될 수 있도록 독립주거 위기대응체계와 사례관리 전략을 마련해야할 것이다. 둘째 연구 측면에서는 본 연구참여자들이 긍정적인 변화와 경험들을 보고한 만큼, 향후 회복관점을 포함 한 다양한 관점에서 독립주거의 효과성에 대한 연구가 필요할 것이며, 이를 통해 주거서비스의 제도적 지원을 위한 근거를 마 련해야 할 것이다. 또한 독립주거 대상자 가족 경험 연구를 통 해 만성 또는 초발 환자 가족 대비 이들 가족의 경험과 요구들 을 확인하고 타당한 가족 중재 전략을 마련해야 할 것이다. 셋 째, 정책 측면에서는 안전한 위치에 질 좋은 주택을 충분히 확 보하기 위해, 법적, 제도적 정책이 마련되어야하며, 이를 위해 공공의 적극적인 관심이 필요하다. 또한 경제적 요인이 독립주 거 유지에 걸림돌이 되지 않도록 고용상황을 고려한 탄력적 재 정지원과 같은 세밀한 정책적 뒷받침이 마련되어야할 것이다.

\section{결 론}

정신장애인을 위한 주거는 과거 입원과 시설 보호에서 최근 지지주거모형으로 확대되고 있다. 보다 독립적인 선상으로의 주거서비스인 독립주거는 주택과 정신건강의 양 측면이 균형 을 이루어야 하는데, 본 연구를 통해 이 두 가지 측면의 본질을 구체적으로 이해할 수 있었다. 즉, 삶의 전환점으로서 주택 그 자체의 필요성과 중요성을 확인하였으며, 당사자 본인과 가족 의 긍정적인 회복 경험, 그리고 이면에 심리적, 기능적, 자기보 호 측면에서의 도전과 한계들이 있었다. 따라서 결론적으로, 공공은 주택마련 확대하기 위한 제도와 정책 마련을 위해 노력 해야 할 것이다. 아울러 정신건강 전문가들은 회복증진 기반 독 립주거 사례관리 모형을 개발하여 독립주거를 성공적으로 유 지하기 위해 필요한 회복증진, 위기관리, 적절한 지지, 고용과 재정 사이의 균형 등 독립적인 삶에 내재된 요인들이 어느 한
쪽도 간과되지 않고 지지될 수 있도록 역할을 보다 전문성 있고 세밀하게 수행해나가야 할 것이다.

\section{CONFLICTS OF INTEREST}

The authors declared no conflicts of interest.

\section{ORCID}

Kim, Hee Jung

Oh, Hee-Young

Lee, Hyeon-Joo

https://orcid.org/0000-0001-6555-1813 https://orcid.org/0000-0003-1897-4850 https://orcid.org/0000-0002-0753-3040

\section{REFERENCES}

1. Kwon OY. A survey on the status of community residence and treatment of people with mental disabilities. National Human Rights Commission of Korea Publication Report [Internet]. 2018 [cited 2021 May 24]. Available from: http://hdl.handle.net/20.500.12236/23544

2. Bae EM, Park HJ. A study of supportive housing experiences for mentally disabled people. Korea Social Welfare Quality Study [internet]. 2017[cited 2021 May 24]. 11(1):59-87. Available from: http://www.dbpia.co.kr/Article/NODE07131735

3. Kim HJ, Oh HY, Lee HJ. Case managers' experience of providing housing services to independent residential mentally disabled people. Stress. 2020;28(4):221-229.

https://doi.org/10.17547/kjsr.2020.28.4.221

4. Padgett D, Gulcur L, Tsemberis S. Housing first services for people who are homeless with co-occurring serious mental illness and substance abuse. Research on Social Work Practice. 2006;16(1):74-83. https://doi.org/10.1177/1049731505282593

5. Aubry T, Nelson G, Tsemberis S. Housing first for people with severe mental illness who are homeless: a review of the research and findings from the at home-chez soi demonstration project. The Canadian Journal of Psychiatry. 2015;60(11):467-474. https://doi.org/10.1177/070674371506001102

6. Rog D, Marshall T, Dougherty R, George P, Daniels A, Ghose S, et al. Permanent supportive housing: assessing the evidence. Psychiatric Services. 2014;65(3):287-294. https://doi.org/10.1176/appi.ps.201300261

7. O'Hara A. Housing for people with mental illness: update of a report to the president's new freedom commission. Psychiatric. Services. 2007;58:907-913.

https://doi.org/10.1176/ps.2007.58.7.907

8. Ridgway P, Zipple A. The paradigm shift in residential services: from the linear continuum to supported housing approaches. Psychosocial Rehabilitation Journal. 1990;13(4):11. https://doi.org/10.1037/h0099479

9. Lee JM. A phenomenological study of the independent living 
experience of people with mental disabilities [master's thesis]. [Daegu]: Daegu University; 2012. 67 p.

10. Nelson G, Aubry T, Lafrance A. A review of the literature on the effectiveness of housing and support, assertive community treatment, and intensive case management interventions for persons with mental illness who have been homeless. American Journal of Orthopsychiatry. 2007;77(3):350-361. https://doi.org/10.1037/0002-9432.77.3.350

11. Gyeonggi-do residential delivery system protocol: focus on the community conversion facilities and independent housing operation. Gyeonggi-do Mental Health and Welfare Center; 2020.

12. Seo GD. A study on the independent living experience of the mentally handicapped. Mental Health and Social Services [dissertation]. [Seoul]: Soongsil University; 2008. 147 p.

13. Shim KS, Cha TY. A qualitative case study on the successful experience of independent living in the community of mentally disabled people. Korea Social Welfare Quality Study. 2019;13 (3):5-31. https://doi.org/10.22867/kaqsw.2019.13.3.5

14. Downe-Wamboldt B. Content analysis: method, applications, and issues. Health Care for Women International. 1992;13(3): 313-334. https://doi.org/10.1080/07399339209516006

15. Guba EG. Criteria for assessing the trustworthiness of naturalistic inquiries. Educational Communication and Technology Journal. 1981:29(2):75-91. https://doi.org/10.1007/BF02766777

16. Barbato A, D'Avanzo B, Harvey C, Lesage A, Maone A. From residential care to supported housing. Frontiers in Psychiatry. 2020;11:560. https://doi.org/10.3389/fpsyt.2020.00560

17. Corrigan P. Place-then-train: an alternative service paradigm for persons with psychiatric disabilities. Clinical Psychology: Science and Practice. 2001;.8(3):334. https://doi.org/10.1093/clipsy.8.3.334

18. Leamy M, Bird V, Le Boutillier C, Williams J, Slade M. Conceptual framework for personal recovery in mental health: systematic review and narrative synthesis. The British Journal of Psychiatry. 2011;199(6):445-452. https://doi.org/10.1192/bjp.bp.110.083733

19. Medalia A, Brekke J. In search of a theoretical structure for understanding motivation in schizophrenia. Schizophrenia Bulletin. 2010;36(5):912-918. https://doi.org/10.1093/schbul/sbq073

20. Yoo SH, Sung JM. A qualitative exploratory study of the process of adapting to residential programs supported by the mentally disabled. Korea Academy Of Mental Health Social Work Spring Conference; 2005 May 11; Daejeon metropolitan cityhall. Daejeon; 2005. p. 383-404.

21. Wu H, Yang C, Chen Y. The role of self-efficacy in the recovery trajectory of mental health consumers. The British Journal of Social Work. 2021;51(3):907-926.

https://doi.org/10.1093/bjsw/bcab025

22. Silván F, Holgado P, Jiménez J, Pérez D. Benefits of employment in people with mental illness: differential mediating effects of internalized stigma on self-esteem. Journal of Community \& Applied Social Psychology. 2021;1-16. https://doi.org/10.1002/casp.2552

23. Watson J, Fossey E, Harvey C. A home but how to connect with others? a qualitative meta-synthesis of experiences of people with mental illness living in supported housing. Health \& Social Care in The Community. 2019;27(3):546-564. https://doi.org/10.1111/hsc.12615

24. Katz, N. Cognition \& occupation across the life span: Models for intervention in occupational therapy. 2nd ed. America Bethesda: American Occupational Therapy Association Press; 2005. 425 p.

25. Kim YS, Park JH, Lee SA. Is a program to improve groceryshopping skills clinically effective in improving executive function and instrumental activities of daily 17 living of patients with schizophrenia?. Asian Journal of Psychiatry. 2020;48:101896. https://doi.org/10.1016/j.ajp.2019.101896

26. National Mental Health Center. Suicide of mentally disabled [National Mental Health Status Report]. 2019 [cited June 24]; 9:1-2. Available from:

http://www.nmhc.or.kr/ezboard.php?BID=board102\&GID= root\&mode=view \&UID=12\&CURRENT_PAGE=1\&SEARCH TITLE $=\&$ searchkeyword $=\&$ category $=\&$ syso $p=\& \mathrm{fm}=\&$ BType $=\&$ ListMax $=$

27. Song SY, Lee YP. A study on the factors affecting suicidal ideation in people with mental disabilities. The Journal of the Korea Contents Association, 2021;21(5):765-775. https://doi.org/10.5392/JKCA.2021.21.05.765

28. Koutra K, Vgontzas A, Lionis C, Triliva S. Family functioning in first-episode psychosis: a systematic review of the literature. Social Psychiatry and Psychiatric Epidemiology. 2014;49(7): 1023-1036. https://doi.org/10.1007/s00127-013-0816-6

29. Kuipers E, Bebbington P, Dunn G, Fowler D, Freeman D, Watson $\mathrm{P}$, et al. Influence of carer expressed emotion and affect on relapse in non-affective psychosis. British Journal of Psychiatry. 2006;188:173-179.

https://doi.org/10.1192/bjp.bp.104.007294

30. Choi HC, Bae EM. A study on the performance of early adaptation support program for people with mental illness living in independent housing: focused on comparing housing types. Journal of Convergence for Information Technology. 2021;11 (1):91-101. https:// doi.org/10.22156/CS4SMB.2021.11.01.091 